\title{
TERAKTIVASI SINTESIS DAN UJI TOKSISITAS SENYAWA ANALOG KALKON TURUNAN 3'-METOKSIASETOFENON DENGAN 3,4- DIMETOKSIBENZALDEHID
}

\author{
Riki Setiawan ${ }^{1}$, Hilwan Yuda Teruna ${ }^{2}$ dan Adel Zamri ${ }^{3}$ \\ 1. Mahasiswa Program S1 Kimia FMIPA Universitas Riau \\ 2,3. Dosen Jurusan Kimia FMIPA Universitas Riau \\ e-mail: adel.zamri@lecturer.unri.ac.id
}

\begin{abstract}
ABSTRAK
Senyawa kalkon merupakan senyawa bahan alam golongan flavonoid yang telah banyak dilaporkan memiliki aktivitas biologis yang beragam. Senyawa ini tersususn atas dua cincin aromatik yang diubungkan oleh suatu sistem karbonil $\alpha, \beta$ tak jenuh. Beberapa bioaktivitas senyawa kalkon yang diketahui diantaranya adalah antiinflamasi, antitumor, antioksidan dan antimikroba. Senyawa (E)-3-(3,4-dimetoksifenil)-1-(3'-metoksifenil)prop-2-en-1-on disintesis menggunakan metoda iradiasi gelombang mikro dari bahan dasar 3,4-dimetoksibenzaldehid dan 3'metoksiasetofenon dalam pelarut etanol absolut dengan banuan katalis basa berupa $\mathrm{KOH}$. Analisis struktur senyawa yang diperoleh dilakukan dengan menggunakan spektroskopi UV, FTIR, HRMS dan ${ }^{1} \mathrm{H}-\mathrm{NMR}$. Rendemen senyawa yang diperoleh yaitu $76,60 \%$. Hasil uji toksisitas menunjukkan potensi antikanker senyawa ini dengan nilai $\mathrm{LC}_{50}=$ $79,268 \mu \mathrm{g} / \mathrm{mL}$.
\end{abstract}

Kata Kunci: kalkon, gelombang mikro, sintesis dan toksisitas

\section{PENDAHULUAN}

Kalkon merupakan salah satu jenis metabolit sekunder golongan flavonoid yang dihasilkan oleh tumbuhan dan merupakan senyawa flavonoid paling sederhana. Kalkon adalah salah satu golongan flavonoid yang memiliki sistem cincin terkonjugasi dengan ikatan rangkap $\mathrm{C}=\mathrm{C}$ dan $\mathrm{C}=\mathrm{O}$. Sistem terkonjugasi ini secara teori memiliki panjang gelombang di sekitar tampak sehingga diperkirakan senyawa ini akan memiliki warna yang khas (Budimawarti \& Handayani, 2010). Senyawa kalkon merupakan 1,3-difenil-2-propen-1-on. Kedua cincin aromatik pada senyawa tersebut dihubungkan oleh 3 atom karbon yang merupakan suatu sistem karbonil $\alpha, \beta$ tak jenuh (Patil et al, 2009).<smiles>O=C(C=Cc1ccccc1)c1ccccc1</smiles>

(1)

Senyawa kalkon mengandung gugus etilen keto $(-\mathrm{CO}-\mathrm{CH}=\mathrm{CH}-)$ yang reaktif seperti terlihat pada gambar struktur umum senyawa kalkon (1).
Adanya gugus tersebut menyebabkan molekul kalkon mempunyai berbagai macam aktivitas biologis (Jayapal et al., 2010). Beberapa contoh bioaktivitas senyawa kalkon misalnya sebagai antiinflamasi (Rahman, 2011), antitumor (Mukesh et al., 2007), antikanker (Rullah, 2011), antioksidan (Ahmed et al., 2011), antijamur (Yuharmen et al, 2011), dan antibakteri (Eryanti et al., 2010).

Variasi struktur senyawa kalkon di alam sangat terbatas. Hal ini menyebabkan kajian terhadap aktivitas biologisnya masih terbatas pada senyawa-senyawa dengan variasi struktur tertentu. Untuk meningkatkan kajian terhadap aktivitas biologis tersebut, maka diperlukan variasi struktur dari senyawa kalkon yang lebih beragam. Metoda sintesis merupakan suatu cara yang dianggap mampu memberikan solusi terhadap permasalahan ini. Metoda sintesis lebih efektif untuk menghasilkan senyawa kalkon yang penggunaannya lebih maksimal. Metoda sintesis juga dapat menghasilkan berbagai struktur analog kalkon yang lebih variatif sehingga dapat diuji potensi aktivitas biologisnya. 
Sintesis senyawa kalkon mulanya dilakukan dengan menggunakan metode sintesis konvensional dengan cara pengadukan (stirrer), gerus, dan refluks. Seiring dengan perkembangan teknologi dibidang sintesis senyawa organik, maka digunakanlah metode sintesis nonkonvensional dengan bantuan radiasi gelombang mikro (microwave). Metode ini dianggap lebih menguntungkan karena dapat mempercepat waktu reaksi dengan cara menurunkan energi aktivasinya. Pertimbangan inilah yang kemudian menjadi dasar pemilihan metode sintesis senyawa kalkon pada penelitian ini. Penelitian ini dilakukan untuk mensintesis senyawa kalkon dari 3'-metoksiasetofenon dengan 3,4-dimetoksibenzaldehid dan uji toksisitasnya dengan metode Brine Shrimp Lethality Test (BSLT).

\section{METODOLOGI PENELITIAN}

\section{Alat dan Bahan}

Peralatan yang digunakan dalam penelitian ini adalah UV-Vis (UVmini-1240 SHIMADZU, spektrofotometer tipe Spectroquant Pharo 300, SEM (ZEISS)EVO-50, oven (Memmert), hotplate (REXIM RSH-IDR AS ONE), sentrifuge, stirrer, desikator, pengaduk magnet, ayakan 200 mesh, neraca analitis, dan peralatan gelas sesuai prosedur kerja.

\section{Bahan dan Peralatan}

Bahan-bahan yang digunakan dalam penelitian ini adalah: 3'-metoksi asetofenon<smiles>COc1cccc(C(C)=O)c1</smiles><smiles>COc1ccc(C=O)cc1OC</smiles>

Gambar 1. Sintesis senyawa kalkon dan air laut.

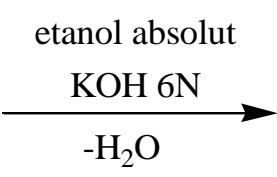

(Merck), 2,3-dimetoksi benzaldehid (Merck), Kalium hidroksida $(\mathrm{KOH}) 6 \mathrm{~N}$, etil asetat (EtOAc), n-heksana, metanol, kloroform, etanol absolut, asam klorida $(\mathrm{HCl}) \quad 3 \mathrm{~N}$, dimetilsulfoksida (Merck), aquades, indikator universal, telur udang (Artemia salina Leach),

Alat-alat yang digunakan dalam penelitian ini adalah sebagai berikut, microwave Samsung ME 109F, pompa vakum, corong buchner, plat KLT $\mathrm{GF}_{254}$, alat pengukur titik leleh Fisher John, bejana KLT (chamber), lampu UV (254 dan $366 \mathrm{~nm}$ ), pipet mikro, neraca analitik, kromatografi kolom, High Performance Liquid Chromatography (HPLC) Shimadzu LC solution jenis kolom Shim-pack VP-ODS dengan panjang dan diameternya yaitu 150x4,6 mm, spektrofotometer UV-Visible (Genesys 10S UVVIS v4.002 2L9N175013) spektroskopi Inframerah (FTIR Shimadzu, IR Prestige-21), spektroskopi NMR (Aglient $500 \mathrm{MHz}$ ), spektroskopi Massa (MS water LCT premier XE mode positif) dan alat-alat gelas laboratorium yang umum digunakan dalam penelitian.

\section{Rancangan Penelitian}

Sintesis senyawa kalkon dilakukan dalam satu tahapan reaksi kondensasi Claisen-Schimdt antara 3'-metoksiasetofenon dengan 3,4dimetoksibenzaldehid dengan bantuan katalis $\mathrm{KOH}$ dalam pelarut enanol absolut seperti terlihat pada Gambar 1.<smiles>COc1cccc(C(=O)/C=C/c2ccc(OC)c(OC)c2)c1</smiles>

\section{Prosedur Kerja Sintesis}

Senyawa 3'-metoksiasetofenon (5 mmol) dimasukkan ke dalam Erlenmeyer $250 \mathrm{~mL}$, ditambahkan etanol absolut ( $5 \mathrm{~mL}$ ) dan $\mathrm{KOH} 6 \mathrm{~N}$ (5 mL). Kemudian campuran reaksi ini ditambahkan dengan senyawa 3,4dimetoksibenzaldehid (5 mmol). Campuran ini kemudian diiradiasi gelombang mikro selama 9 menit. Tahapan reaksi dipantau dengan uji KLT setiap 1 menit. Produk sintesis kemudian ditambahkan aquades dingin sebanyak $15-20 \mathrm{~mL}$ dan setetes demi setetes larutan $\mathrm{HCl} 3 \mathrm{~N}$ hingga pH menjadi netral. Campuran reaksi ini kemudian diekstraksi dengan menggunakan kloroform untuk memisahkan produk dari pelarutnya. Produk yang telah terpisah dari pelarut ini kemudian dimurnikan dengan kromatografi kolom menggunakan silika $\mathrm{GF}_{60}$ (70-230 Mesh) dan eluen yang sesuai. Uji kemurnian dilakukan dengan KLT, uji titik leleh dan analisis kemurnian menggunakan HPLC. 


\section{Uji Toksisitas dengan Metode Brine Shrimp Lethality Test (BSLT)}

Larutan induk dibuat dengan konsentrasi $10000 \mu \mathrm{g} / \mathrm{mL}$ dengan cara melarutkan $20 \mathrm{mg}$ sampel dalam $2 \mathrm{~mL}$ metanol. Larutan induk ini kemudian diencerkan bertingkat untuk memperoleh konsentrasi $1000 \mu \mathrm{g} / \mathrm{mL}, \quad 100$ $\mu \mathrm{g} / \mathrm{mL}$ dan $10 \mu \mathrm{g} / \mathrm{mL}$. Kemudian disiapkan vial kosong yang sudah dikalibrasi volum $5 \mathrm{~mL}$. Sampel dipipet ke dalam masing-masing vial sebanyak $0,5 \mathrm{~mL}$, lalu pelarut diuapkan hingga mengering. Selanjutnya, ke dalam masingmasing vial ditambahkan $50 \mu \mathrm{L}$ DMSO dan air laut. Sebanyak 10 ekor larva udang yang sudah disiapkan dimasukkan ke dalam vial tersebut dan ditambah air laut hingga batas kalibrasi 5 $\mathrm{mL}$. Tingkat toksisitas diukur dengan cara menghitung jumlah larva udang yang masih hidup dalam selang waktu 24 jam. Pengujian dilakukan sebanyak tiga kali pengulangan dengan perlakuan yang sama untuk masingmasing konsentrasi. Data yang diperoleh dianalisis untuk menentukan nilai $\mathrm{LC}_{50}$ dengan metoda kurva menggunakan Tabel analisis probit.

Kontrol negatif dalam uji BSLT disiapkan, sebanyak $50 \mu \mathrm{L}$ DMSO dipipet dengan pipet mikro dimasukkan kedalam vial dan ditambahkan air laut sedikit. Kemudian dimasukkan 10 ekor larva Artemia salina Leach dan ditambah air laut hingga batas kalibrasi 5 $\mathrm{mL}$.

\section{HASIL DAN PEMBAHASAN Sintesis Senyawa Kalkon}

Penelitian ini mensintesis senyawa senyawa (E)-3-(3, 4- dimetoksifenil)-1-(3' - metoksifenil) prop-2-en-1-on (RS-2). Senyawa RS-2 yang diperoleh ini sulit membentuk padatan, sehingga pemurnian senyawa ini dilakukan dengan menggunakan metoda pemisahan kromatografi kolom. Sebelum dilakukan pemurnian, terlebih dahulu senyawa dipisahkan dari pelarut yang digunakan sa'at dilakukan proses sintesis. Hasil ekstraksi berupa cairan seperti minyak dengan berat total $0,8125 \mathrm{~g}$. Proses pemurnian dengan metoda kromatografi kolom menghasilkan senyawa murni berupa padatan kuning dengan berat $0,6364 \mathrm{~g}$ dan rendemen $76,60 \%$.

Senyawa yang diperoleh kemudian diuji kemurniannya dengan menggunakan plat KLT, uji titi leleh dan analisis HPLC. Hasil uji dengan plat KLT menghasilkan satu noda pada perbandingan eluen $n$-heksana: etil asetat: kloroform (6: 1: 3) dengan harga $R_{f}=0,525$. Hasil ini kemudian didukung dengan uji titik leleh yang memberikan hasil berupa selisih sebesar $1^{\circ} \mathrm{C} \quad\left(52-53^{\circ} \mathrm{C}\right)$. analisis kemurnian dengan HPLC menunjukkan adanya puncak dominan pada $\lambda 258 \mathrm{~nm}, \mathrm{t}_{\mathrm{R}}: 15,635$ menit dan $\lambda$ $366 \mathrm{~nm}, \mathrm{t}_{\mathrm{R}}: 15,637$ menit. Data hasil pengujian dapat dilihat pada Tabel 1.

Tabel 1. Sifat fisik senyawa kalkon

\begin{tabular}{ccccc}
\hline Struktur & $\begin{array}{c}\text { Rumus } \\
\text { Molekul }\end{array}$ & $\begin{array}{c}\text { Rendemen } \\
(\%)\end{array}$ & $\begin{array}{c}\text { Titik } \\
\text { Leleh }\left({ }^{\circ} \mathbf{C}\right)\end{array}$ & $\begin{array}{c}\text { Warna } \\
\text { Kristal }\end{array}$ \\
\hline $\mathrm{OMe}$ & $\mathrm{C}_{17} \mathrm{H}_{16} \mathrm{O}_{4}$ & 76,60 & $52-53$ & Kuning \\
\hline
\end{tabular}

Proses selanjutnya yang dilakukan adalah karakterisasi senyawa RS-2 dengen menggunakan spektroskopi UV, IR ${ }^{1} \mathrm{H}-\mathrm{NMR}$ dan MS. Hal ini dilakukan dengan tujuan memastikan struktur senyawa yang telah berhasil disintesis. Karakterisasi senyawa RS-2 dengan menggunakan spetroskopi UV menghasilkan serapan maksimum pada $\lambda 203$. Hasil ini membuktikan bahwa pada senyawa RS-2 terdapat suatu sistem konjugasi dari cincin aromatik. Serapan maksimum lainnya yaitu pada 
$\lambda 257$ yang mengindikasikan adanya sistem konjugasi cincin A aromatik yang terkonjugasi dengan karbonil. Hasil serapan maksimum yang lainnya adalah pada $\lambda \quad 357$ yang mengindikasikan adanya sistem konjugasi cincin B yang terkonjugasi dengan suatu sistem karbonil $\alpha, \beta$-tak jenuh dan adanya pengaruh dari gugus metoksi.

Karakterisasi selanjutnya dilakukan dengan menggunakan spektroskopi IR. Spektrum IR senyawa RS-2 menunjukkan adanya serapan pada bilangan gelombang $1174,70 \mathrm{~cm}^{-1}$ yang menunjukkan adanya gugu C-OMe. Serapan pada bilangan gelombang $1652,10 \mathrm{~cm}^{-1}$ yang menunjukkan adanya gugus $\mathrm{C}=\mathrm{O}$. Serapan pada bilangan gelombang $1516,11 \quad \mathrm{~cm}^{-1}$ yang menandakan adanya gugus $\mathrm{C}=\mathrm{C}$ aromatis. Serapan selanjutnya ada pada bilangan gelombang $1586,52 \mathrm{~cm}^{-1}$ yang menandakan adanya ikatan $\mathrm{C}=\mathrm{C}$ alkena. Serapan selanjutnya ada pada bilangan gelombang $3084,31 \mathrm{~cm}^{-1}$ yang menandakan adanya ikatan $\mathrm{C}-\mathrm{H}$ aromatis. Data analisis FTIR dapat dilihat pada Tabel 2.

Analisis ${ }^{1} \mathrm{H}-\mathrm{NMR}$ dimaksudkan untuk menentukan struktur senyawa yang telah berhasil disintesis dengan melihat splitting puncak proton yang ada pada senyawa tersebut. Data spektrum ${ }^{1} \mathrm{H}-\mathrm{NMR}$ senyawa RS-2 menunjukkan kesesuaian antara jumlah proton yang terbaca dengan jumlah proton yang diharapkan. Pergeseran kimia pada $\delta 6,90 \mathrm{ppm}$ menunjukkan proton $\mathrm{H}$ pada posisi C-5 dengan pemecahan doublet. Pergeseran kimia pada $\delta$ 7,12 ppm menunjukkan proton $\mathrm{H}$ pada posisi C4' dengan pemecahan doublet of doublet. Proton pada posisi C-4' seharusnya menunjukkan pemecahan doublet, akan tetapi karena adanya pengaruh konektivitas jarak jauh dengan C-6' sehingga menyebabkan pemecahan doublet dari C-4' terpecah kembali menjadi doublet of doublet. Pergeseran kimia $\delta \quad 7,16$ ppm menunjukkan proton pada posisi C-2 dengan pemecahan doublet. Pergeseran kimia pada $\delta$ 7,23 ppm menunjukkan proton $\mathrm{H}$ pada posisi C6 dengan pemecahan doublet of doublet.

Pemecahan ini juga dipengaruhi oleh konektivitas jarak jauh terhadap C-2 sehingga pemecahan yang seharusnya doublet terpecah kembali menjadi doublet of doublet. Pergeseran kimia pada $\delta 7,37 \mathrm{ppm}(d, 1 \mathrm{H}, \mathrm{J}=15,6)$ dan $\delta$ $7,76 \mathrm{ppm}(d, \quad 1 \mathrm{H}, \quad \mathrm{J}=15,650$ berturut-turut menunjukkan proton $\mathrm{H}$ pada posisi $\mathrm{C}_{\alpha}$ dan $\mathrm{C}_{\beta}$. Pergeseran kimia pada $\delta$ 7,41 ppm menunjukkan proton $\mathrm{H}$ pada posisi C-5' dengan pemecahan triplet. Pergeseran kimia pada $\delta$ 7,54 ppm menunjukkan proton $\mathrm{H}$ pada posisi C-2' dengan pemecahan triplet. Pemecahan puncak pada posisi ini seharusnya adalah pemecahan singlet, akan tetapi karena ada pengaruh konektivitas jarak jauh dengan C-6' dan C-4' sehingga menyebabkan puncak singlet terpecah kembali menjadi dua sehingga menjadi triplet. Pergeseran kimia $\delta$ 7,59 ppm menunjukkan proton $\mathrm{H}$ pada posisi C-6' dengan pemecahan doublet. Gugus fungsi metoksi ditunjukkan pada pergeseran kimia $\delta 3,88 \mathrm{ppm}(s, 3 \mathrm{H}, \mathrm{C}-4$ '),$\delta$ $3,93 \mathrm{ppm}(s, 3 \mathrm{H}, \mathrm{C}-3)$ dan $\delta 3,95 \mathrm{ppm}(s, 3 \mathrm{H}, \mathrm{C}-$ 3 '). Data analisis ${ }^{1} \mathrm{H}-\mathrm{NMR}$ dapat dilihat pada Tabel 2.

Tabel 2. Data spektrum FTIR, HRMS dan ${ }^{1} \mathrm{H}-\mathrm{NMR}$ senyawa kalkon

\begin{tabular}{|c|c|c|}
\hline $\begin{array}{c}\text { Data Spektrum }{ }^{1} \mathrm{H}-\mathrm{NMR} \\
\text { (300 MHz, Dimetilsulfoksida, } \delta \text { (ppm)) }\end{array}$ & $\begin{array}{l}\text { Data Spektrum IR } \\
\quad\left(\mathrm{KBr}, \mathrm{cm}^{-1}\right)\end{array}$ & $\begin{array}{c}\text { Data } \\
\text { Spektrum } \\
\text { MS }(m / z)\end{array}$ \\
\hline $\begin{array}{l}6,90 \mathrm{ppm}(d, 1 \mathrm{H}, \mathrm{Ar}-5, J=8,3 \mathrm{~Hz}) ; 7,12 \mathrm{ppm}(d d, \\
\left.1 \mathrm{H}, \mathrm{Ar}-4, J_{\mathrm{a}}=2,05 \mathrm{~Hz} \text { dan } J_{\mathrm{b}}=8,25 \mathrm{~Hz}\right) ; 7,16 \mathrm{ppm}(d, \\
1 \mathrm{H}, \mathrm{Ar}-2-\mathrm{H}, J=1,75 \mathrm{~Hz}) ; 7,23 \mathrm{ppm}(d d, 1 \mathrm{H}, \operatorname{Ar}-6-\mathrm{H}, \\
\left.J_{\mathrm{a}}=1,80 \mathrm{~Hz} \text { dan } J_{\mathrm{b}}=8,30 \mathrm{~Hz}\right) ; 7,37 \mathrm{ppm}\left(d, 1 \mathrm{H}\left(\mathrm{H}_{\alpha}\right),\right. \\
J=15,6 \mathrm{~Hz}) ; 7,76 \mathrm{ppm}\left(d, 1 \mathrm{H}\left(\mathrm{H}_{\beta}\right), J=15,65 \mathrm{~Hz}\right) ; 7,41 \\
\mathrm{ppm}\left(t, 1 \mathrm{H}, \mathrm{Ar}-5{ }^{\prime}-\mathrm{H}, J=7,95 \mathrm{~Hz}\right) ; 7,5419 \mathrm{ppm}(t, 1 \mathrm{H}, \\
\left.\mathrm{Ar}-2^{\prime}-\mathrm{H}, J=2,25 \mathrm{~Hz}\right) ; 7,59 \mathrm{ppm}\left(d, 1 \mathrm{H}, \operatorname{Ar}-6^{\prime}-\mathrm{H}\right) \\
J=7,65 \mathrm{~Hz}) ; 3,88 \mathrm{ppm}\left(s, 3 \mathrm{H}, \mathrm{Ar}-4-\mathrm{OCH}_{3}\right) ; 3,93 \mathrm{ppm} \\
\left(s, 3 \mathrm{H}, \mathrm{Ar}-3-\mathrm{OCH}_{3}\right) \text { dan } 3,95 \mathrm{ppm}\left(s, 3 \mathrm{H}, \mathrm{Ar}-3^{\prime}-\mathrm{OCH}_{3}\right)\end{array}$ & $\begin{array}{lcr}1174,70 & (\mathrm{C}-\mathrm{OMe}) ; & 1652,10 \\
(\mathrm{C}=\mathrm{O}) ; & 1516,11 & (\mathrm{C}=\mathrm{C} \\
\text { aromatis }) ; & 1586,52 & (\mathrm{C}=\mathrm{C} \\
\text { alkena); } & 3084,31 \quad(\mathrm{C}-\mathrm{H} \\
\text { aromatis }) & \text { (Lampiran 10) }\end{array}$ & 299,1284 \\
\hline
\end{tabular}


Analisis spektrum massa (MS) menunjukkan berat molekul senyawa yang telah berhasil disintesis. Berat molekul untuk senyawa RS-2 ditunjukkan oleh spektrum massa sebagai $\mathrm{C}_{18} \mathrm{H}_{19} \mathrm{O}_{4}[\mathrm{M}+\mathrm{H}]^{+}$dengan puncak ion molekul $\mathrm{m} / \mathrm{z} 299,1284$ dan puncak ion molekul yang dihitung secara teoritis adalah 299,1283. Hasil ini menunjukkan adanya selisih massa sebesar 0,0001 . Perbedaan selisih massa yang sangat kecil pada kedua senyawa tersebut menunjukkan bahwa senyawa yang berhasil disintesis sudah dalam keadaan murni. Berdasarkan data-data karakterisasi yang dilakukan maka dapat disimpulkan bahwasannya senyawa yang telah berhasil disintesis sesuai dengan senyawa target yang diharapkan.

\section{Uji Toksisitas}

Senyawa yang telah berhasil disintesis dan telah dikarakterisasi kemudian diuji bioaktivitasnya. Bioaktivitas yang dipilih pada penelitian ini adalah uji toksisitas. Uji aktivitas toksisitas dilakukan dengan menggunakan metoda Brine Shrimp Lethality Test (BSLT) dengan menggunakan larva Artemia salina Leach sebagai hewan uji. Uji ini dipilih karena beberapa keunggulan diantaranya adalah pengerjaan yang sederhana, proses yang relatif cepat, tidak banyak menggunakan sampel dan tidak membutuhkan peralatan yang khusus.

Uji toksisitas RS-2 dilakukan dengan menggunakan berbagai variasi konsentrasi (100, 10, $1 \mu \mathrm{g} / \mathrm{mL}$ ). Penggunaan variasi konsentrasi ini dimaksudkan untuk mengetahui tingkat aktivitas dari senyawa uji terhadap kematian larva Artemia salina Leach dalam waktu 24 jam pengujian. Larutan uji dibuat dengan menggunakan pelarut metanol dengan pertimbangan pelarut ini mudah melarutkan senyawa organik dan mudah menguap. Pada proses pengujian terlebih dahulu pelarut metanol harus diuapkan sempurna. Hal ini dilakukan karena metanol dapat mengganggu hasil pengujian karena metanol juga bersifat toksik. Proses pengujian dilakukan dengan menggunakan air laut sebagai media uji dengan pertimbangan Artemia salina Leach dapat tumbuh dengan baik di dalam air laut. Untuk membantu melarutkan senyawa uji, ke dalam masing-masing vial uji ditambahkan $50 \mu \mathrm{L}$ DMSO (dimetilsulfoksida). DMSO dipilih karena mudah melarutkan senyawa uji dan sifanya yang relatif kurang toksik jika dibandingkan dengan metanol sehingga tidak akan mempengaruhi hasil pengujian. Selain itu konsentrasi DMSO yang digunakan juga sangatlah kecil. Hasil pengujian kemudian dianalisis dengan menggunakan metoda analisis probit. Tingkat potensi toksisitas RS-2 yang ditunjukkan oleh nilai $\mathrm{LC}_{50}$ adalah 79,268 $\mu \mathrm{g} / \mathrm{mL}$.

\section{KESIMPULAN}

Penelitian ini berhasil mensintesis senyawa (E)-3-(3,4-dimetoksifenil)-1-(3'metoksifenil)prop-2-en-1-on dengan rendemen $76,60 \%$. Hasil uji analisis struktur dengan menggunakan spektoskopi UV, FTIR, ${ }^{1} \mathrm{H}-\mathrm{NMR}$ dan HRMS terhadap senyawa kalkon yang telah berhasil disintesis menunjukkan bahwa senyawa yang diperoleh sesuai dengan senyawa target yang diharapkan. Hasil uji toksisitas memberikan hasil $\mathrm{LC}_{50}$ senyawa $\mathrm{RS}-2$ sebesar $79,268 \mu \mathrm{g} / \mathrm{mL}$. Berdasarkan nilai $\mathrm{LC}_{50}$ tersebut dapat diketahui bahwa senyawa RS-2 memiliki potensi sebagai antikanker

\section{DAFTAR PUSTAKA}

Ahmed, R.M., Sastry, G.V., Bano, N., Ravichandra, S., \& Raghavendra, M. 2011. Synthesis and Cytotoxic, Antioxidant Activities of New Chalcone Derivatives. Rasyan Journal of Chemistry. 4(2): 289-294.

Budimawarti, C \& Handayani, S. 2010. Efektivitas katalis asam basa pada sintesis 2-hidroksicalkon, senyawa yang berpotensi sebagai zat warna. Jurdik kimia $U N Y$.

Eryanti, Y., Zamri, A., Jasril dan Rahmita. 2010. Sintesis Turunan 2'-hidroksi Kalkon melalui Kondensasi Claisen-Schmidt dan Uji Aktivitasnya sebagai Antimikroba. Jurnal Natur Indonesia. 12(2): 223-227.

Jayapal, M.R., Prasad, K.S., \& Sreedhar, N.Y. 2010. Synthesis and Characterization of 4Hidroxy Chalcones By Aldol 
Condensation Using $\mathrm{SOCl}_{2} / \mathrm{EtOH}$.

International Journal of Curent

Pharmaceutical Research. 4(2): 60-62.

Mukesh, D., Sivakumar, P.M \& Babu, S.K. 2007. QSAR Studies on Chalcones and Flavonoids as Anti-tuberculosis Agents Using Genetic Function Approximation (GFA) Method. Department of Biotechnology, Indian Institute of Technology Madras; Chennai 600036, India.

Patil, C.B., Mahajan, S.K., \& Katti, S.A. 2009. Chalcone: A Versatile Molecule. Journal of Pharmaceutical Science and Research. 1(3): 11-12.
Rahman, M.A. 2011. Chalcone: A Valuable Insight into the Recent Advances and Potential Pharmacological Activities. Chemical Sciences Journal. 29: 1-16.

Rullah, K. 2011. Sintesis Senyawa Calkon Dan Turunannya dengan Pendekatan Green Synthesis Serta Uji Preklinik Antikanker Secara In Vitro dan In Vivo. Tesis tidak diterbitkan. Program Pascasarjana UR, Riau.

Yuharmen., Eryanti, Y. Zamri, A., Rahmad, A. 2011. Sintesis Beberapa Senyawa Analog Calkon Menggunakan Katalis $\mathrm{SOCL}_{2}$ dan Uji Aktivitas sebagai Antimikroba. Jurnal Teknobiologi. 2(1):71-76. 